\title{
IMPLANTE MEDIATO APÓS TRAUMA DE AVULSÃO DENTÁRIA ASSOCIADO COM ENXERTO ÓSSEO E GENGIVAL: RELATO DE CASO
}

\section{MEDIATE IMPLANT AFTER TRAUMA TOOTH AVULSION ASSOCIATED WITH BONE AND GINGIVAL GRAFTS: CASE REPORT}

\author{
José Lacet de LIMA-JÚNIOR* \\ José Arão da SILVA-FILHO** \\ Julliana Cariry Palhano FREIRE** \\ Eduardo DIAS-RIBEIRO*....
}

\begin{abstract}
RESUMO
As deformidades dentofaciais causadas por traumas necessitam de enxertos ósseos para a correção dos defeitos e posterior instalação de implantes dentários. Os enxertos autógenos, por apresentarem propriedades de osteogênese, osteoindução e osteocondução, são considerados o padrão ouro. Devido ao processo competitivo de osteogênese e fibrogênese, membranas absorvíveis e não absorvíveis podem ser associadas para otimizar regeneração óssea guiada, evitando a invasão do tecido mole no sítio ósseo. Os enxertos de tecido conjuntivo subepiteliais associados aos enxertos ósseos favorecem a estética e melhoram a faixa de gengiva ceratinizada. O objetivo do presente estudo foi relatar um caso clínico de implante mediato após trauma de avulsão dentária associado com enxerto ósseo e mucoso vascularizado oriundo do palato. Conclui-se que houve resultado satisfatório com a aplicação da técnica.
\end{abstract}

Descritores: Transplante autólogo • Transplante ósseo • Materiais biocompatíveis.

\section{ABSTRACT}

Dentofacial deformities caused by trauma require bone grafts to correct the defects and subsequent installation of dental implants. Autografts for presenting properties of osteogenesis, osteoinduction and osteoconductive are considered the gold standard. Due to the competitive process of osteogenesis and fibrogenesis, absorbable and nonabsorbable membranes can be attached to optimize guided bone regeneration, avoiding soft tissue invasion in the bone site. The subepithelial connective tissue grafts associated with bone grafts favor the appearance and improves the range of keratinized gingiva. The aim of this study was to report a case of mediate implant after tooth avulsion trauma associated with bone and mucosal graft vascularized derived palate. It was concluded that there was satisfactory result with the application of the technique.

Descriptors: Transplantation, autologous • Bone transplantation • Biocompatible materials.

* Coordenador do Curso de Especialização em Cirurgia e Traumatologia Bucomaxilofaciais (CTBMF), Sindicato dos Odontologistas do estado da Paraíba (SINDODONTO/PB), João Pessoa-PB; Cirurgião e Traumatologista Bucomaxilofaciais do Hospital de Emergência e Trauma Senador Humberto Lucena (HETSHL), João Pessoa-PB; Especialista em CTBMF pela Associação Paulista de Cirurgiões-Dentistas (APCD), Bauru-SP; Mestre em Clínica Odontológica pela Universidade Potiguar, Natal-RN.

** Especialista em Cirurgia e Traumatologia Bucomaxilofaciais (SINDODONTO/PB), João Pessoa-PB.

*** Cirurgiã-Dentista e Mestranda em Ciências Odontológicas, Programa de Pós-graduação em Odontologia, Universidade Federal da Paraíba (UFPB), João Pessoa-PB.

**** Professor Adjunto do Curso de Odontologia, Unidade Acadêmica de Ciências Biológicas, Universidade Federal de Campina Grande (UFCG), campus de Patos-PB. eduardodonto@yahoo.com.br 
LIMA-JÚNIOR JL

SILVA-FILHO JA

FREIRE JCP

DIAS-RIBEIRO E

IMPLANTE

MED I ATO

APÓS TRAUMA

DE AVULSÃO

DENTÁRIA

ASSOCIADO COM

ENXERTO ÓSSEO

E GENGIVAL:

RELATO DE CASO

76

REV, ODONTOL.

UNIV, CID, SÃO

PAULO

2016; 29(1): $81-9$,

$J A N-A B R$

\section{IN TRODUÇÃ 0}

Apesar dos avanços na tecnologia dos biomateriais, o enxerto ósseo autógeno ainda é melhor material de enxertia dos maxilares, sendo considerado o padrão ouro para reconstrução óssea ${ }^{1,2}$. Da mesma forma, obtêm-se melhor qualidade na neoformação óssea e menor tempo de cicatrização, em relação a outros métodos de enxertia óssea ${ }^{3,4,5,6,7}$.

Quando falamos em reparos e/ou processos de cicatrização há de se notar que o que ocorre no osso difere do que ocorre nos tecidos moles. Naquele pode-se dizer que ocorre uma neoformação do tecido, com características semelhantes ao que havia anteriormente (osteogênese), enquanto neste ocorre apenas um reparo, com formação de um tecido mais rico em fibras (fibrinogênese), resultando num tecido diferente do que havia anteriormen$\mathrm{te}^{2,8}$.

Dentre os enxertos, o autógeno sobressai em relação aos demais por ser o único capaz de promover a osteogênese, ou seja, é o único capaz de estimular a formação do osso, diretamente a partir dos osteoblastos preexistentes. Além disso, simultaneamente, possui a propriedade de induzir a diferenciação das células mesenquimais indiferenciadas em osteoblastos e condroblastos, aumentando a formação óssea no local (osteoindução). Ainda serve de arcabouço para a aposição de um novo tecido ósseo em sua superfície (osteocondução) $)^{1,2,9,10,11 .}$

Contudo, ele não reúne as características para ser considerado como um enxerto ideal, o qual deve obedecer aos seguintes requisitos: fornecimento ilimitado sem comprometer a área doadora; não apresentar resposta imunológica do hospedeiro; revascularizar rapidamente; ser substituído completamente por osso em quantidade e qualidade semelhante ao do hospedeiro ${ }^{1,5,9, \text {. }}$

Na reabilitação com implantes dentários, outra modalidade de enxertos pode ser utilizada: os de tecidos moles. Nesse sentido, o cirurgião pode lançar mão dos enxertos conjuntivos, vascularizados ou livres. O enxerto de tecido conjuntivo submucoso é capaz de aumentar o metabolismo no sítio receptor, preservando ou aumentando a quantidade da gengiva ceratinizada, a partir das células epiteliais adjacentes ao enxerto. A formação da gengiva ceratinizada ao redor dos implantes endósseos é de fundamental importância para a manutenção do selamento biológico peri-implantar e consequente sobrevida do implante em longo prazo. Várias técnicas e biomateriais têm sido utilizados em conjunto com enxerto de tecido conjuntivo submucoso para obtenção de melhores resultados. A regeneração óssea guiada e a utilização de enxertos ósseos, combinados ao enxerto de tecido conjuntivo têm contribuído para o aumento e manutenção do rebordo, redução dos defeitos pós-exodontia, instalação de implantes imediatos, tratamento da recessão, fenestração e patologia peri-implantar ${ }^{12,13,14}$.

Outro material bastante utilizado em associação com os enxertos ósseos são as membranas. Apresentam também grande versatilidade de adaptação, o que os enxertos ósseos não possuem. Já como desvantagens podemos citar os riscos de infecção e dificuldade de remoção devido à formação de tecidos fibrosos e pontes ósseas $2,13,15,16,17$.

Objetivou-se no presente estudo apresentar um caso clínico de implante mediato após trauma de avulsão dentária associado com enxerto ósseo e mucoso vascularizado oriundo do palato.

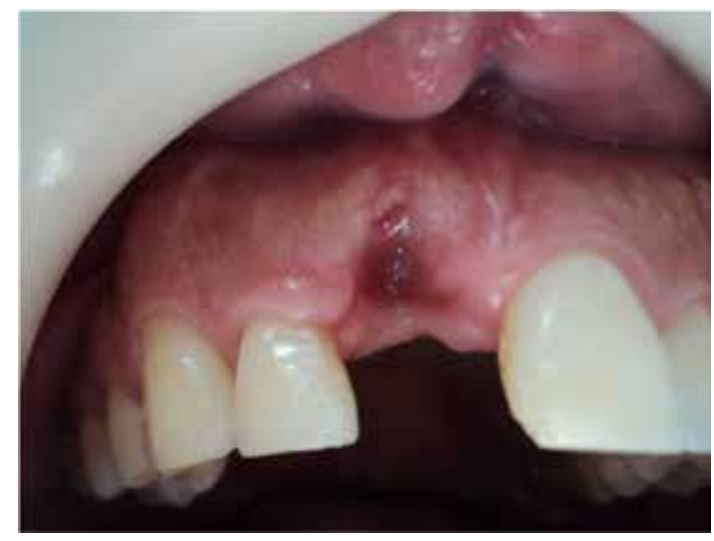

Figura 1. Aspecto clínico do defeito causado pelo trauma de avulsão do incisivo central superior direito. 


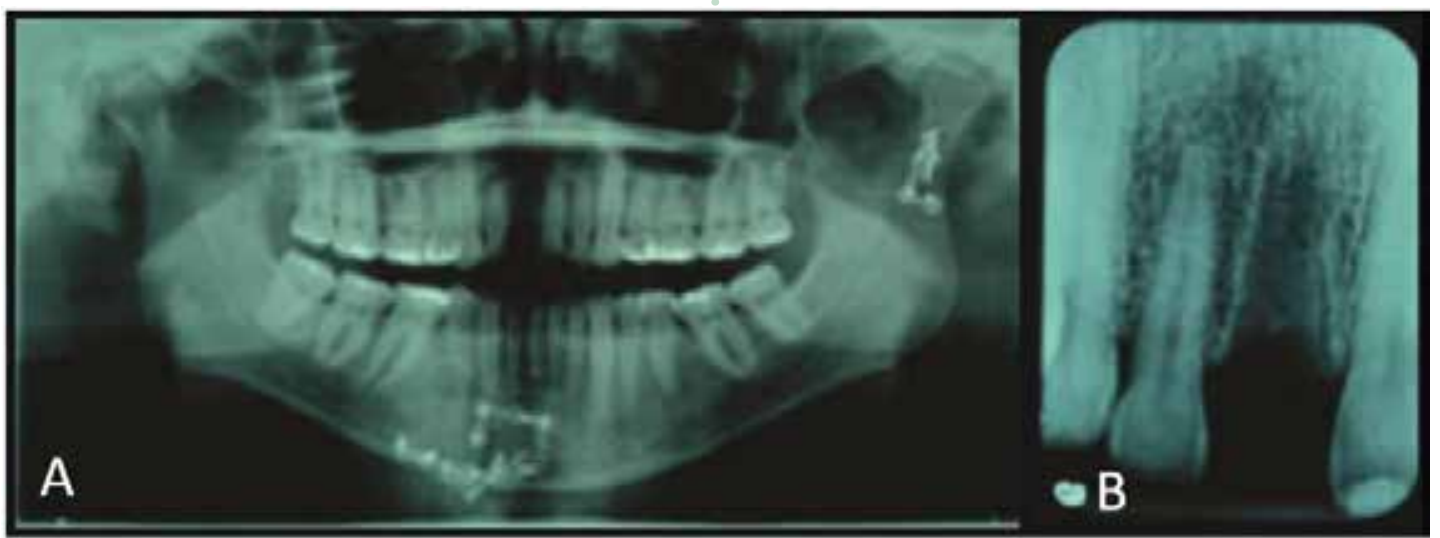

Figura 2 A-B. Aspecto radiográfico do pós-cirúrgico da fratura mandibular e pós-trauma dentoalveolar (avulsão dentária).

\section{RELATO DE CASO}

Paciente leucoderma, 29 anos, com histórico de acidente motociclístico, atendido do Hospital de Emergência e Trauma Senador Humberto Lucena (HETSHL), em João Pessoa-PB. Ao exame clínico e radiográfico, constataram-se fratura exposta e bilateral da mandíbula, bem como fratura alvéolo-dentária superior com avulsão traumática do incisivo central superior direito. No primeiro atendimento, foi realizada a cirurgia para redução e fixação das fraturas mandibulares, porém, como não foi encontrado o elemento avulsionado no local do acidente, optou-se pelo tratamento conservador do alvéolo e posterior reabilitação com implante (Figuras 1 e 2 A-B) Após quinze dias da primeira cirurgia realizou-se o procedimento implantodôntico na clínica-escola da Especialização em Cirurgia e Traumatologia Bucomaxilofaciais do SINDODONTO-PB, em João Pessoa-PB. Previamente constatou-se perda da tábua óssea vestibular no alvéolo correspondente ao incisivo central superior direito por meio de exame clínico e radiográfico. Assim, realizou-se a cureta-
LIMA-JÚNIOR JL

SILVA-FILHO JA

FREIRE JCP

DIAS-RIBEIRO E

IMPLANTE

MEDIATO

APÓS TRAUMA

DE AVULSÃO

DENTÁRIA

ASSOCIADO COM

ENXERTO ÓSSEO

E GENGIVAL:

RELATO DE CASO

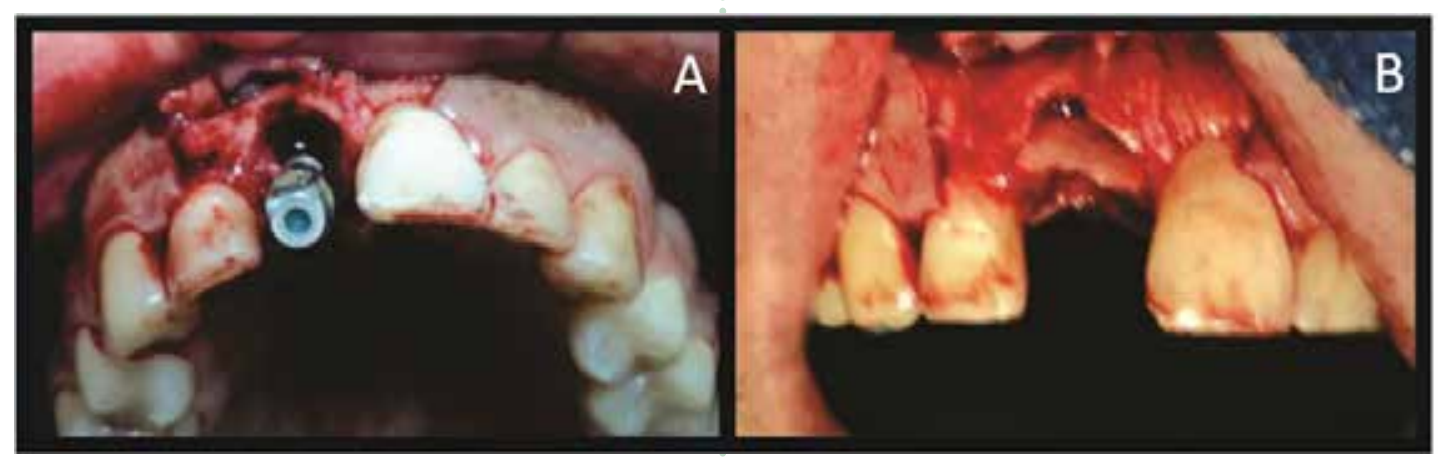

Figura 3 A-B. Aspecto clínico do implante e enxerto ósseo.

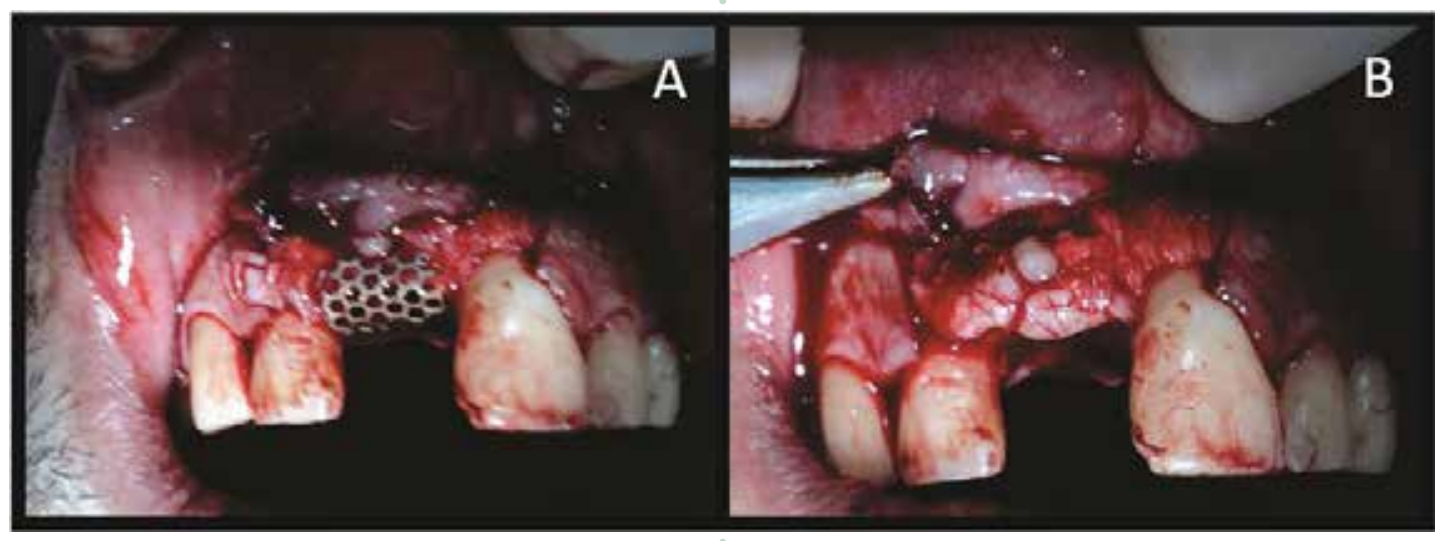

Figura 4 A-B. Micromalha de titânio e enxerto vascularizado de mucosa palatina.

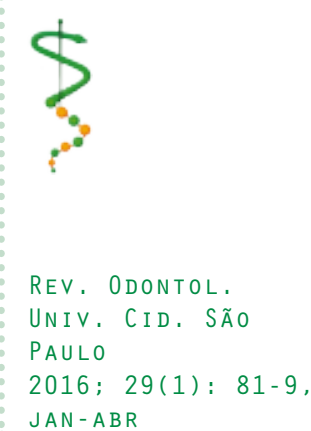


LIMA-JÚNIOR JL $S I L V A-F I L H O \quad J A$ FREIRE JCP DIAS-RIBEIRO E

IMPLANTE MEDI ATO

APÓS TRAUMA

DE AVULSÃO

DENTÁRIA ASSOCIADO COM ENXERTO ÓSSEO

E GENGIVAL: RELATO DE CASO gem alveolar e instalação de implante cônico com hexágono interno, apresentando $3,75 \mathrm{~mm}$ de diâmetro por $13 \mathrm{~mm}$ de altura (Implante Conexão®, Arujá-SP, Brasil) associado com enxerto autógeno obtido da linha oblíqua mandibular. Em seguida, foi instalada micromalha de titânio com perfurações de 0,9mm de diâmetro. Após a fase óssea da cirurgia, foi girado um retaIho dividido do palato, recobrindo a micromalha de titânio. O retalho vestibular foi suturado sobre o enxerto de tecido conjuntivo vascularizado, recobrindo-o totalmente e corrigindo o defeito (Figuras 3 A-B e 4 A-B). Foram prescritas as seguintes medicações: iniciando com uso profilático de $1 \mathrm{~g}$ de Amoxicilina, 1 hora antes do procedimento e continuando por mais 5 dias de Amoxicilina 500mg de 8/8 horas; Nimesulida $100 \mathrm{mg}$ de $12 / 12$ horas por 05 dias; Tramadol 50 mg de 6/6 horas, em caso de dor.

Paciente retornou após 7 dias para acompanhamento e remoção das suturas, e observou-se cicatrização satisfatória.
Após o período de osseointegração do implante (4 meses), o paciente retornou para que fosse feita a remoção da micromalha de titânio, procedimento de reabertura e instalação do cicatrizador (Implante Conexão®, Arujá-SP, Brasil). Por fim, observa-se o aspecto clínico e radiográfico do paciente com prótese fixa provisória sobre o implante, verifica-se bom contorno gengival e aspecto saudável da gengiva inserida (Figuras 5 A-B e 6 A-B).

\section{DISCUSSÃO}

Quanto às áreas doadoras intrabucais, algumas vantagens são relatadas na obtenção de enxerto do ramo da mandíbula em relação ao mento, principalmente devido às queixas e complicações pós-operatórias $1,2,5,6,11$. Quanto às desvantagens de obtenção de enxerto do ramo da mandíbula, apontam-se o difícil acesso e a possibilidade lesar o feixe vásculo-nervoso alveolar inferior ${ }^{1,2,5,6,11}$. Outra vantagem se refere ao uso de enxertos de origem membranosa (calota craniana e mandíbula) em

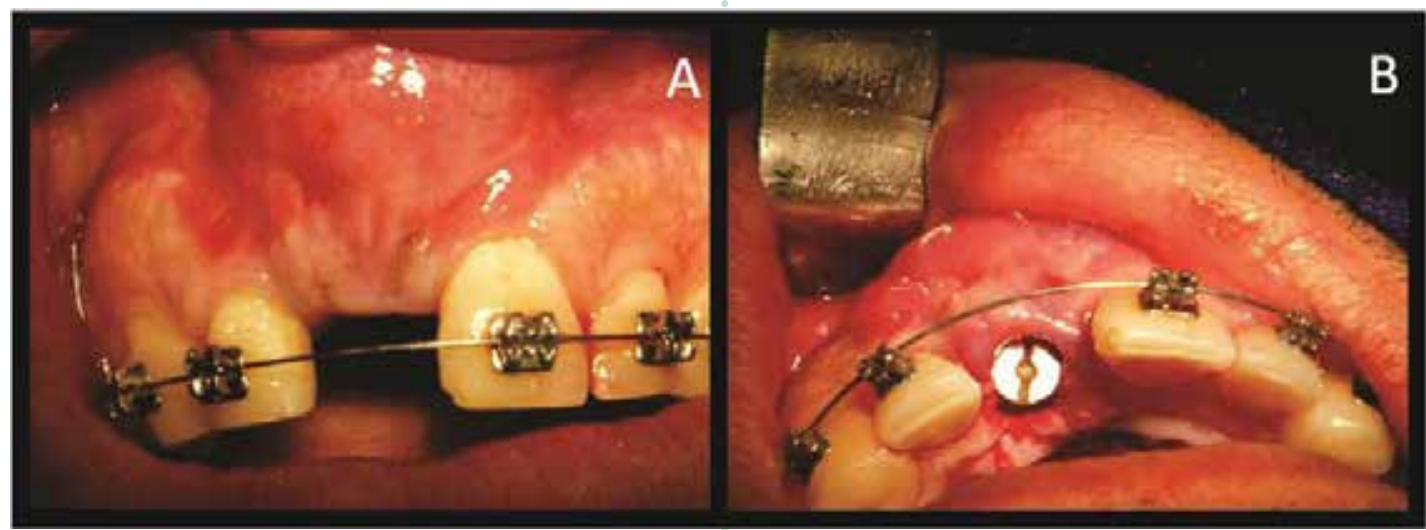

Figura 5 A-B. Imagem do rebordo gengivval e cicatrizador.

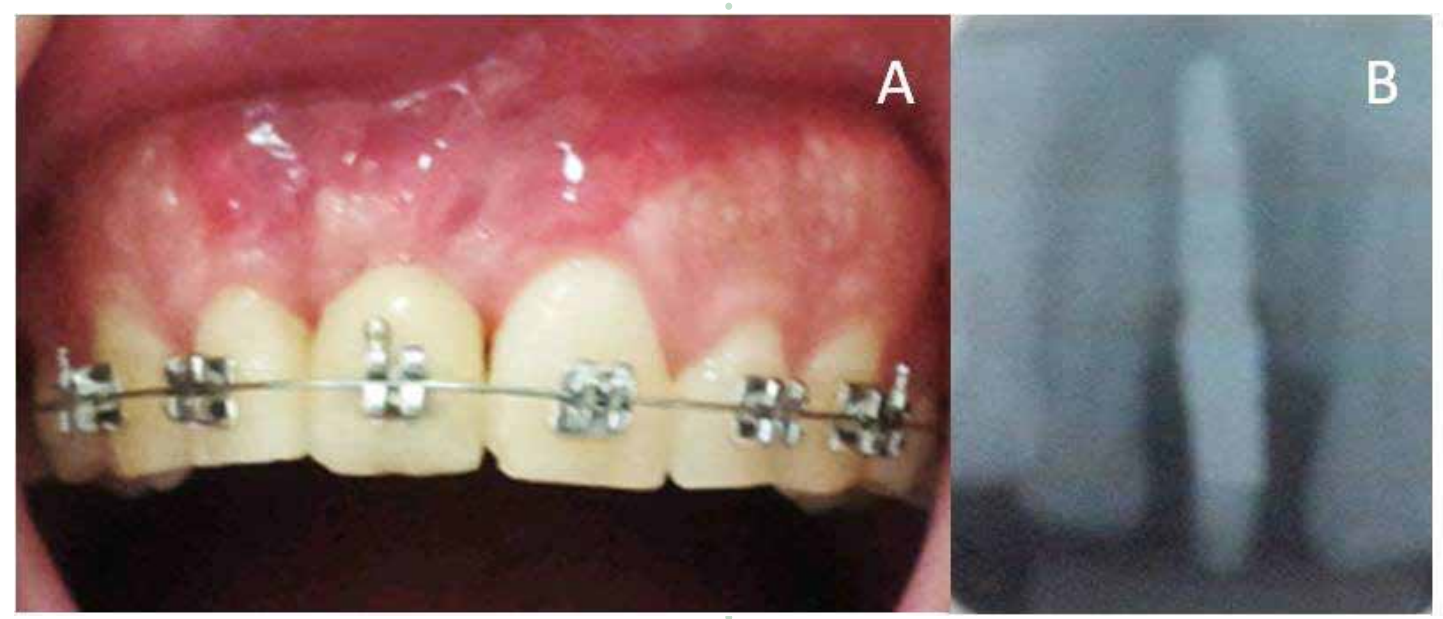

Figura 6 A-B. Aspecto clínico e radiográfico do provisório. 
relação à de origem endocondral (ilíaco, tíbia e costela) quando se considera a reabsorção óssea. Essa diferença provavelmente deve-se à característica mais cortical do osso de origem membranosa ${ }^{3,7,18}$.

Em relação à regeneração óssea guiada, membranas rígidas ou com reforço de titânio são capazes de promover a formação de quantidade significativa de novo osso e manter espaço suficiente, sem a adição de material de preenchimento ${ }^{17}$. Isso ocorre devido à sua capacidade de "efeito tenda", ou seja, o arcabouço formado ${ }^{17}$. Membranas absorvíveis também podem ser utilizadas e têm como vantagem a eliminação de uma segunda cirurgia, necessária para sua remoção, assim como um trauma para os novos tecidos formados. Alguns exemplos dessas membranas são as colágenas, de dura-máter, de copolímeros de glicose e lactose, de ácido polilático e poliuretano $^{14}$. Apesar das diferenças entre as membranas absorvíveis e não absorvíveis, alguns estudos não demonstram diferenças significativas entre elas ${ }^{15,16}$.
Quanto aos tecidos moles peri-implantares, Aroeira ${ }^{12}$ afirma que a utilização do enxerto de tecido conjuntivo subepitelial otimiza biotipos periodontais finos, meIhorando a quantidade e a qualidade da mucosa ao redor dos implantes bem como resulta em estética adequada e estabilidade do tecido mole peri-implantar ${ }^{13,14}$.

No caso clínico apresentado, o implante é dito mediato porque foi colocado num segundo momento posterior ao trauma e à avulsão do elemento dentário. Ao contrário, se tivesse sido colocado imediatamente à avulsão do elemento dentário, seria chamando implante imediato.

\section{CONSIDERAÇÕES FINAIS}

De acordo com a literatura levantada e a técnica aplicada conclui-se que houve resultado satisfatório. Os implantes mediatos associados aos enxertos ósseos e mucosos são favoráveis no processo de reparo de perdas teciduais no trauma alvéolo-dentário (avulsão), reabilitando a estética, devolvendo a função e melhorando o aspecto psicossocial dos pacientes.
LIMA-JÚNIOR JL

SILVA-FILHO JA FREIRE JCP

DIAS-RIBEIRO E

IMPLANTE

MEDIATO

APÓS TRAUMA

DE AVULSÃO

DENTÁRIA

associado cOM

enxerto ósseo

E GENGIVAL:

RELATO DE CASO

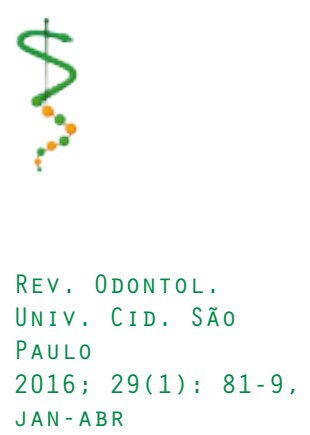




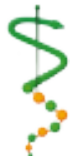

REV, ODONTOL. UNIV, CID, SÃO PAULO
1. Anchieta AE. Enxerto ósseo autógeno intraoral na implantodontia [Monografia]. São José do Rio Preto: Centro Universitário do Norte Paulista; 2007.

2. Fardin AC, Jardim ECG, Pereira FC, Guskuma MH, Aranega AM, Garcia Júnior IR. Enxerto ósseo em odontologia: revisão de literatura. Innov Implant J Biomater Esthet (Online) 2010 dez;5(3):48-52.

3. Dado DV, Izquierdo R. Absorption of onlay bone grafts in immature rabbits: membranous versus enchondral bone and bone struts versus paste. Annals of plastic surgery 1989 Jul;23(1):39-48.

4. Intini G, Andreana S, Buhite RJ, Bobek LA. A comparative analysis of bone formation induced by human demineralized freeze-dried bone and enamel matrix derivative in rat calvaria critical-size bone defects. Journal of periodontology 2008 Jul;79(7):1217-24.

5. Kuabara MR, Vasconcelos LW, Carvalho PSP. Técnicas cirúrgicas para obtenção de enxerto ósseo autógeno. Rev Fac Odontol Lins 2000 jan-dez. 12((1/2)):44-51.

6. Misch CM. Ridge augmentation using mandibular ramus bone grafts for the placement of dental implants: presentation of a technique. Practical periodontics and aesthetic dentistry : PPAD 1996 Mar;8(2):127-35; quiz 38.

7. Phillips JH, Rahn BA. Fixation effects on membranous and endochondral onlay bone-graft resorption. Plastic and reconstructive surgery 1988 Nov;82(5):872-7.

8. Peterson LJ, Ellis E, Hupp JR, Tucker MR. Cirurgia oral e maxilofacial contemporânea. Rio de Janeiro: Elsevier; 2005.

9. Gomes KU, Carlini JL, Biron C, Rapoport A, Dedivitis RA. Use of allogeneic bone graft in maxillary reconstruction for installation of dental implants. Journal of oral and maxillofacial surgery : official journal of the American Association of Oral and Maxillofacial Surgeons 2008 Nov;66(11):2335-8.
10. Roshna T. Implant with simultaneous bone grafting for replacement of maxillary anterior tooth: a case report. People's J Scient Res 2010 3(2):41-4.

11. Taylor G. Intra-oral autogenous bone grafting for dental implant site preparation. Dent Bullet 2010 15(3):12-4.

12. Aroeira P. Utilização do enxerto de tecido conjuntivo subepitelial na implantodontia [Monografia]. Rio de Janeiro: Centro de Pós-Graduação da Academia de Odontologia do Rio de Janeiro; 2007.

13. Gupta S, Deo V, Williams C. Interproximal Papillae Reconstruction around Implant Using Subepithelial Connective Tissue Graft in Maxillary Anterior Region: A Case Series. Journal of oral \& maxillofacial research 2012 3(2):e1.

14. Lindhe J, Karring T, Lang NP. Tratado de periodontia clínica e implantologia oral. Rio de Janeiro: Guanabara Koogan; 2005.

15. Caffesse RG, Mota LF, Quinones CR, Morrison EC. Clinical comparison of resorbable and non-resorbable barriers for guided periodontal tissue regeneration. Journal of clinical periodontology 1997 Oct;24(10):747-52.

16. Eickholz P, Pretzl B, Holle R, Kim TS. Long-term results of guided tissue regeneration therapy with non-resorbable and bioabsorbable barriers. III. Class II furcations after 10 years. Journal of periodontology 2006 Jan;77(1):88-94.

17. Jovanovic SA, Nevins M. Bone formation utilizing titanium-reinforced barrier membranes. The International journal of periodontics \& restorative dentistry 1995 Feb;15(1):56-69.

18. Zins JE, Whitaker LA. Membranous versus endochondral bone: implications for craniofacial reconstruction. Plastic and reconstructive surgery 1983 Dec;72(6):778-85.

Recebido em 30/08/2016

Aceito em 08/12/2016 